\title{
First Identification and Genotyping of Enterocytozoon bieneusi and Prevalence of Encephalitozoon intestinalis in Patients with Acute Diarrhea in the Republic of Korea
}

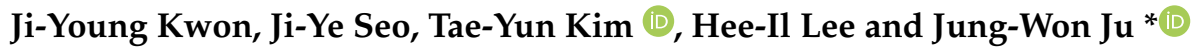 \\ Division of Vectors and Parasitic Diseases, Korea Disease Control and Prevention Agency, \\ 187 Osongsaenmyeong2-ro, Osong-eup, Heungdeok-gu, Cheongju 28159, Chungbuk, Korea; \\ kjiy31@korea.kr (J.-Y.K.); seojiye02@korea.kr (J.-Y.S.); kty4588@korea.kr (T.-Y.K.); isak@korea.kr (H.-I.L.) \\ * Correspondence: jupapa@korea.kr; Tel.: +82-4-3719-8521
}

\section{check for} updates

Citation: Kwon, J.-Y.; Seo, J.-Y.; Kim, T.-Y.; Lee, H.-I.; Ju, J.-W. First Identification and Genotyping of Enterocytozoon bieneusi and Prevalence of Encephalitozoon intestinalis in Patients with Acute Diarrhea in the Republic of Korea. Pathogens 2021, 10, 1424. https://doi.org/10.3390/ pathogens 10111424

Academic Editor: Jacob

Lorenzo-Morales

Received: 13 October 2021

Accepted: 1 November 2021

Published: 3 November 2021

Publisher's Note: MDPI stays neutral with regard to jurisdictional claims in published maps and institutional affiliations.

Copyright: (c) 2021 by the authors. Licensee MDPI, Basel, Switzerland. This article is an open access article distributed under the terms and conditions of the Creative Commons Attribution (CC BY) license (https:/ / creativecommons.org/licenses/by/ $4.0 /)$.
Abstract: Encephalitozoon intestinalis and Enterocytozoon bieneusi can cause diarrhea in humans, especially severe diarrhea in immunocompromised patients. However, there have been few studies on Enc. intestinalis and Ent. bieneusi in patients with acute diarrhea in the Republic of Korea (ROK). In this study, fecal samples were collected from 1241 patients with acute diarrhea in 2020. Among these, 24 cases of Enc. intestinalis and one case of Ent. bieneusi were detected via PCR amplification of small subunit ribosomal RNA. Genotyping of the internal transcribed spacer region sequence revealed that the detected Ent. bieneusi genotype was in Group 1. This study provides the first evidence that Ent. bieneusi exists in humans in addition to animals in the ROK. To identify the causative agent, continuous monitoring of Enc. intestinalis and Ent. bieneusi is necessary for patients with acute diarrhea in the ROK.

Keywords: Encephalitozoon intestinalis; Enterocytozoon bieneusi; patient; genotype; phylogeny; microsporidia; acute diarrhea; Republic of Korea; prevalence rate

\section{Introduction}

Microsporidia, which include more than 170 genera and 1300 species, are opportunistic protozoan pathogens that infect a variety of vertebrate and invertebrate hosts [1] Enterocytozoon, Pleistophora, Encephalitozoon, Vittaforma, Trachipleistophora, Brachiola, Nosema, and Microsporidium have been reported to infect humans. Encephalitozoon intestinalis and Enterocytozoon bieneusi are known to be the most common cause of intestinal diseases [2,3]. Microsporidia are present everywhere and spread through various routes [4]. Microsporidia that infect humans have been identified in animals and water sources [5], and species infecting humans also infect animals, raising the concern for zoonotic transmission [6]. In particular, a direct evidence for zoonotic transmission of microsporidiosis has been reported in a child after close contact with Enc. cuniculi-infected pups [7]. In addition, spores present in stools of infected individuals can be transmitted horizontally through fecal-oral transmission or ingestion of contaminated food and water $[6,8]$.

Microsporidia infections occur mainly in immunocompromised patients, such as patients with HIV, organ transplant recipients, and patients with cancer. Of 68 patients with HIV suffering from diarrhea in the United States, 25 and 5 were infected with Ent. bieneusi and Enc. intestinalis, respectively [9]. Of 97 patients with HIV in Germany, 18 and 2 were infected with Ent. bieneusi and Enc. intestinalis, respectively [10]. In Mali, 8 of 61 patients with HIV were infected with Ent. bieneusi [11]. In addition to immunocompromised patients, microsporidia infections have been continuously reported worldwide in immunocompetent individuals, including children, travelers, and the elderly [12,13]. In Mexico, 20 of 255 immunocompetent individuals were infected with Enc. intestinalis [14], while 39 of 1201 were infected with Ent. bieneusi in China [15]. Moreover, 14 of 275 pregnant women in 
France were infected with Enc. intestinalis [16]. Of 100 children with diarrhea in Gabon, 15 were infected with Enc. intestinalis and two with Ent. bieneusi [17]. Similarly, three were infected with Enc. intestinalis and four with Ent. bieneusi of 70 healthy individuals in Slovakia [18].

In the Republic of Korea (ROK), little research on microsporidia has been reported. In 2011, seven cases of Enc. intestinalis were detected among 139 patients with diarrhea [19]. However, no human Ent. bieneusi infections have been reported in the ROK, despite infections in wild animals (e.g., water deer and raccoon dogs) and livestock (pigs and calves) [20-23]. The purpose of this study was to investigate the prevalence of Enc. intestinalis and Ent. bieneusi and identify their genotypes in the ROK.

\section{Results}

\subsection{Prevalence of Enc. intestinalis and Ent. bieneusi}

Among the 1241 stool samples examined in this study, 24 were positive for Enc. intestinalis and one for Ent. bieneusi (Table 1). We analyzed other divisions to check for co-infections with bacteria and viruses that could cause diarrhea. Of the 24 Enc. intestinalis cases, only one patient was confirmed to be co-infected with Staphylococcus aureus. The single patient infected with Ent. bieneusi was confirmed to be co-infected with Campylobacter spp. Additional results on other parasites, bacteria, and viruses detected during this study will be published later.

Table 1. Encephalitozoon intestinalis and Enterocytozoon bieneusi infection rates.

\begin{tabular}{lccc}
\hline Protozoa Parasite & Total & Enc. intestinalis (\%) & Ent. bieneusi (\%) \\
\hline Number of Samples & 1241 & $24(2.0 \%)$ & $1(0.1 \%)$ \\
Sex & Total & Enc. intestinalis (\%) & Ent. bieneusi (\%) \\
Male & 648 & $12(1.9 \%)$ & $1(0.2 \%)$ \\
Female & 593 & $12(2.0 \%)$ & - \\
Age Group (Years) & Total & Enc. intestinalis (\%) & Ent. bieneusi (\%) \\
$0-9$ & 281 & $3(1.1 \%)$ & - \\
$10-19$ & 86 & $3(3.5 \%)$ & $1(1.2 \%)$ \\
$20-29$ & 43 & $2(4.7 \%)$ & - \\
$30-39$ & 46 & $3(6.5 \%)$ & - \\
$40-49$ & 77 & $2(2.6 \%)$ & - \\
$50-59$ & 144 & $1(0.7 \%)$ & - \\
$60-69$ & 202 & $5(2.5 \%)$ & - \\
$\geq 70$ & 362 & $5(1.4 \%)$ & $1(0.1 \%)$ \\
Total & 1241 & $24(2.0 \%)$ & - \\
\hline
\end{tabular}

Enc. intestinalis was detected in 12 male $(12 / 648,1.9 \%)$ and 12 female $(12 / 593,2.0 \%)$ patients. In contrast, Ent. bieneusi was detected in only a single male patient $(1 / 648,0.2 \%)$. Enc. intestinalis infection was not associated with $\operatorname{sex}(p=0.8$, odds ratio $=0.91,95 \%$ confidence interval $=0.41-2.05)$. The prevalence of Enc. intestinalis was highest in the $30-39$ age group (6.5\%), followed by the 20-29 (4.7\%) and 10-19 (3.5\%) age groups. Ent. bieneusi was detected in the 10-19 age group, with a prevalence of $1.2 \%$ (Table 1 ).

\subsection{Sequence Analysis of Enc. intestinalis and Ent. bieneusi Using Small Subunit Ribosomal RNA}

Enc. intestinalis and Ent. bieneusi DNA fragments were sequenced using both the forward and reverse primers Mic C and Mic D. All 24 cases of Enc. intestinalis (KDCA 1-24) showed 100\% similarity with the small subunit ribosomal RNA (SSU rRNA) gene and were clustered with previously reported isolates (Accession numbers: KM058742, DQ453122, and JF932507), based on their molecular phylogenies. The SSU rRNA sequence of the single Ent. bieneusi case (KDCA 25) was also clustered with previously reported isolates (Accession numbers: MG976584, MH027470, and KJ019869) (Figure 1). 
KDCA 25

MG976584 Eastern grey kangaroo Australia

MH027470 Human Malaysia

99

KJ019869 Effluent wastewater China

KF305580 Cynomolgus monkey China

JQ769381 Sheep China

MT474002 Raccoon China

MW011751 Bamboo rat China

KDCA 1-24

29

KM058742 Human Poland

DQ453122 Fox Ireland

37

JF932507 Human Pakistan

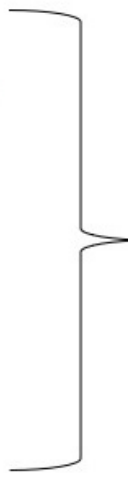

Ent. bieneusi

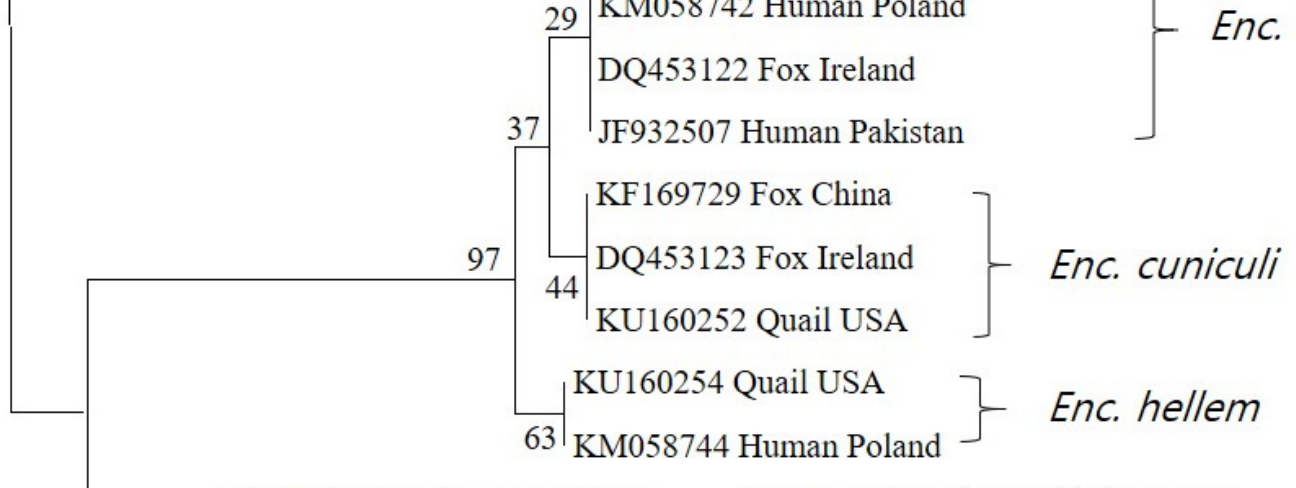

JF443599 Bombyx mori China — Nosema bombycis (Outgroup)

0.05

Figure 1. Phylogenetic tree of Encephalitozoon spp. and Enterocytozoon bieneusi isolates and selected accessions from GenBank, based on small subunit ribosomal RNA gene fragment sequences. The phylogenetic tree was constructed using nucleotide sequence alignments, with the Kimura two-parameter algorithm as the distance method and neighbor-joining as the tree composition method. The black squares indicate the known genotypes identified in this study. The sequence of Nosema bombycis was used as the outgroup.

\subsection{Genotype of Ent. bieneusi}

Based on the sequencing analysis of the internal transcriptional spacer (ITS) gene, we detected one Ent. bieneusi genotype, Korea-WL2. The KDCA25 Ent. bieneusi isolate obtained in the present study was identical to LC436502 from a raccoon dog and LC436503 from a Korean water deer in the ROK [20]. KDCA25 showed one nucleotide substitution at position $230(\mathrm{~T} / \mathrm{G}$ ) compared to existing genotype D sequences (Figure 2). Phylogenetic analysis was carried out to understand the genetic relationships among the Ent. bieneusi genotypes. A neighbor-joining tree was constructed using the Ent. bieneusi ITS nucleotide sequences from humans and domestic animals. KDCA25 was clustered into Group 1, the human pathogenic group (Figure 3). 


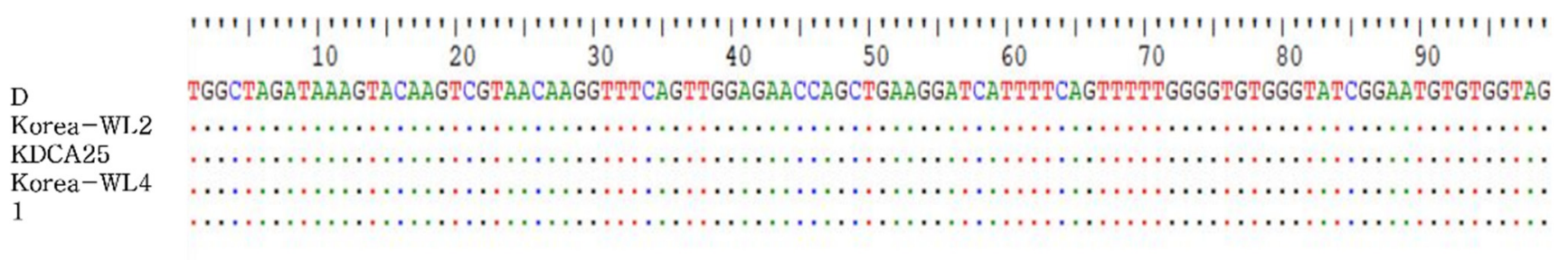

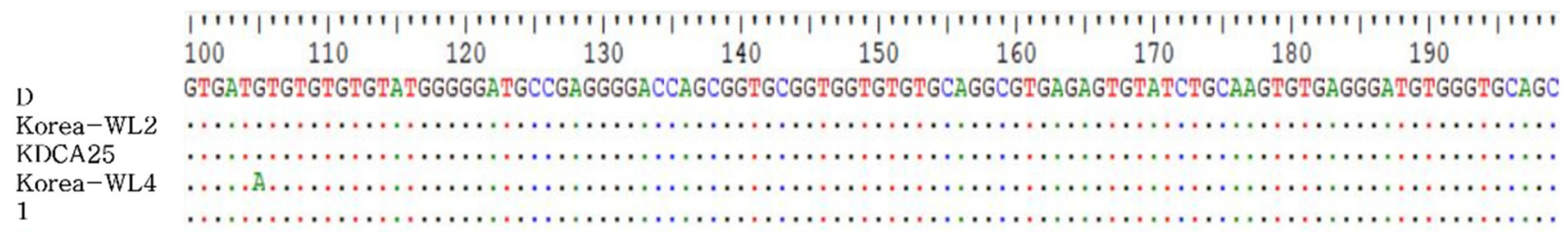

D

\begin{tabular}{|c|}
\hline $200 \quad 210$ \\
\hline
\end{tabular}

GAGTTAGAGGTGGTTCATGTGGAATAGTGGGATIGGTACGTGATGGTTGGATGGGGGAATGATGTGIGTATGGGTGAGGAAAATCGGAGGTGCGGTGC

Korea-WL2

KDCA25

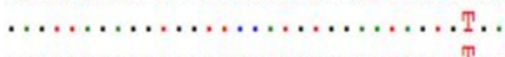

Korea-WL4

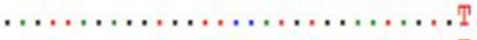

1



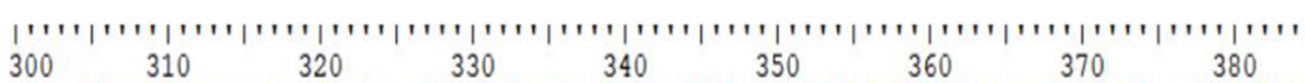

D GGAGGTTGCGGTGCGAGCGGCAGTAGGGTGCCATCAAGAGGTGTATMTGGAAATATCCCTAATACAGGATCACTTGGATCCGTCG

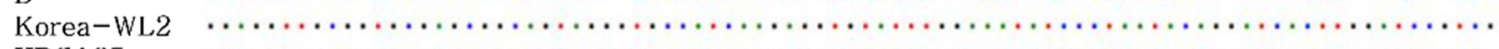

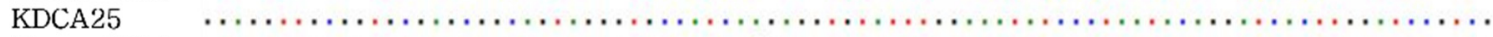

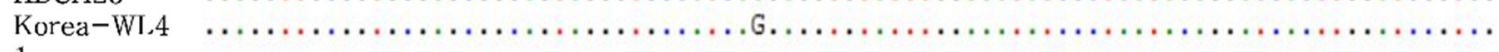

1

Figure 2. Sequence based on internal transcriptional spacer (ITS) sequences. Position of nucleotide changes within Enterocytozoon bieneusi genotype D-related sequences compared to that in MK696083 (D), LC436503 (Korea WL-2), LC436512 (Korea WL-4), and MN922367(1). Each sequence is identified by its genotype designation. Sequence differences of ITS sequences obtained in this study are shown. "." indicates an identical nucleotide to MK696083 (D). 


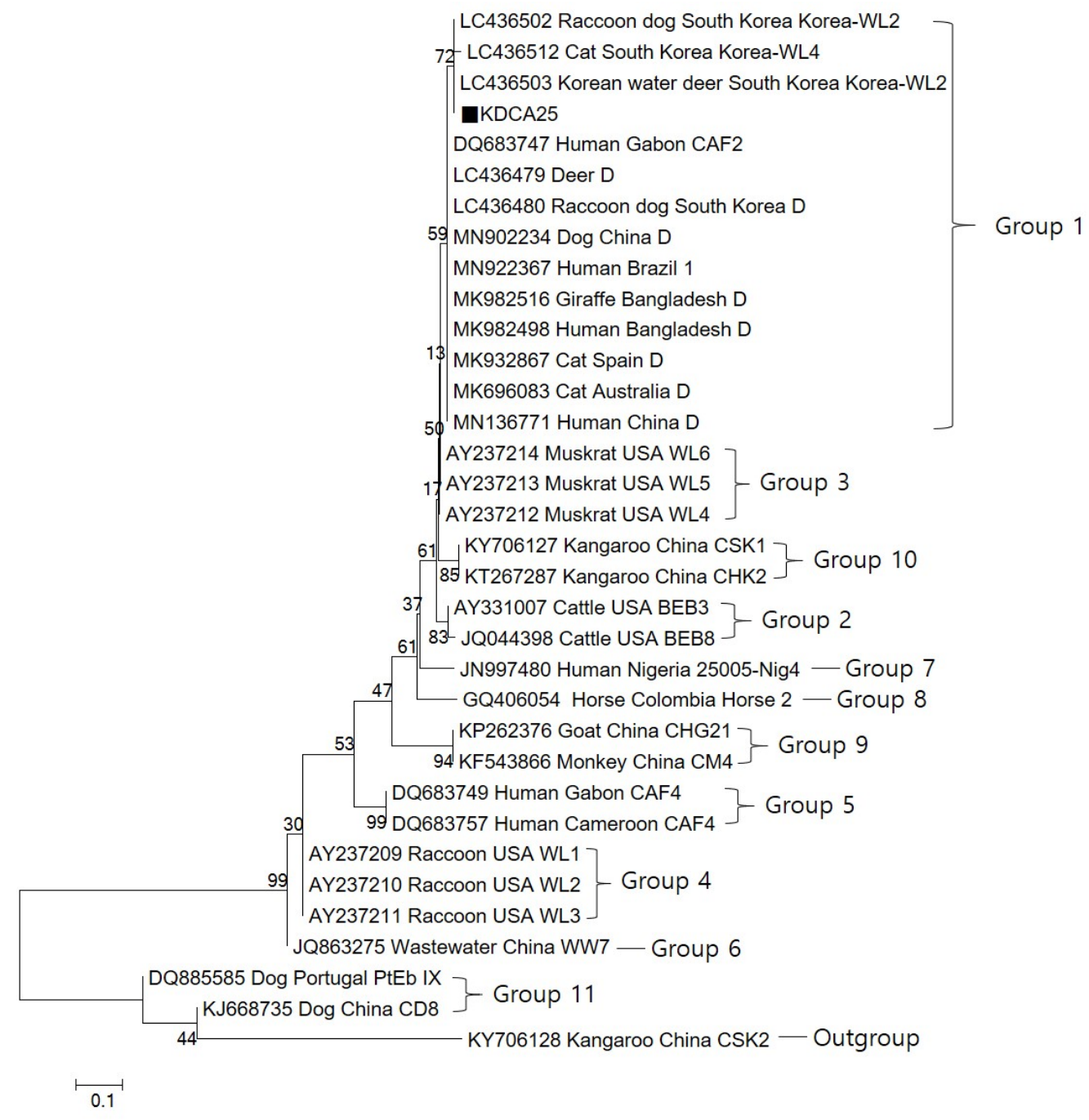

Figure 3. Phylogenetic tree based on neighbor-joining analysis of internal transcriptional spacer (ITS) sequences. The phylogenetic relationships between the Enterocytozoon bieneusi genotype determined in this study and previously reported genotypes from GenBank were inferred by neighbor-joining analysis of ITS sequences, based on Kimura two-parameter model genetic distances. The numbers on the branches are percentage bootstrapping values from 1000 replicates. Each sequence is identified by its accession number, host, origin, and genotype designation. The black square indicates the known genotype identified in this study.

\section{Discussion}

Ent. bieneusi and Enc. intestinalis are both common microsporidia species responsible for gastrointestinal diseases in humans [24]. Ent. bieneusi is the most common microsporidial cause of intestinal diseases [25]. However, Enc. intestinalis showed a higher infection rate than Ent. bieneusi in the ROK. This could have two possible explanations. First, the detection rate depends on patient condition. Ent. bieneusi infection accounts for $30-51 \%$ of all cases of diarrhea in immunocompromised patients [26]. Previous studies on Enc. intestinalis and Ent. bieneusi focused on immunocompromised patients. Although this study focused on immunocompetent patients with diarrhea, it is necessary to include immunocompromised patients as a control group in future studies. Second, developed countries have reported gradual decreases in the prevalence and occurrence of Ent. bieneusi in immunocompromised patients due to the use of antiretroviral therapies and improved hygiene [27]. 
In 2015, Kim et al. [19] reported a 5\% (7/139) prevalence of Enc. intestinalis in patients with diarhhea in the ROK; however, we found a prevalence of $2 \%(24 / 1241)$. In this study, the infection rate was high in the 20-29 (2/43, 4.7\%) and 30-39 (3/46,6.5\%) age groups. However, in previous studies, the infection rates were high in the 11-20 (4/15, 26.7\%) and $31-40(1 / 5,20 \%)$ age groups. In addition, no infection rate was reported for the 21-30 age group by Kim et al. [19] as it contained only one sample, while 20-29 group had the second-highest prevalence in this study. We believe that sampling differences could have affected the low prevalence in this study. As no data related to the infection sources or other clinical information are available for the positive cases in the previous study, it is difficult to explain the differences between our results and those of the previous study.

The ITS domain of rRNA genes is the only known polymorphic marker of Ent. bieneusi. At least 474 ITS genotypes have been discovered, which can be systematically classified into 11 groups (Groups 1-11), with Group 1 and 2 being the major groups [28,29]. At least 38 ITS genotypes have been found in the ROK (including genotype D, H, I, J, BEB2, BEB4, BEB8, CAF1, CEbA, CEbB, CEbC, CEbD, CEbE, CEbF, EBITS3, EBITS4, EBITS5, EbpC, KBAT1, KBAT2, KBAT3, KBAT4, KCALF1, KCALF2, KBEB5, KWB1, KWB2, KWB3, KWB4, WL1, WL2, WL3, WL4, WL5, WL6, PigEBITS9, Type IV, and Peru2) and they belong to Group 1 and Group 2 [20-23,30-32]. The genotypes in Group 1 have a wide host range, including humans and numerous mammals, indicating low host specificity and possibility for zoonotic or cross-species transmission [33]. According to previous studies, the genotypes of Group 2 are specific to cattle [34], and those of Group 3 and 4 are specific to muskrat and raccoons [35]. Group 5 also infects humans, including genotype CAF4, which was found in HIV-positive and HIV-negative patients in Gabon and Cameroon [36]. Group 6 contains genotypes found in urban wastewater in China [37], while Group 7 genotypes have been found in HIV-positive patients in Nigeria [38]. Groups 8-11 consist mainly of animal host genotypes [29,39].

In this study, the Ent. bieneusi isolate (KDCA 25) belonged to Group 1. The sequence matched with those previously reported from domestic wildlife [19], suggesting a possible infection through fecal-oral route via contaminated water, the environment, or food from domestic wildlife [35]. There have been no previously reported cases of Ent. bieneusi in the ROK, except for domestic and wild animals. Previous studies on Ent. bieneusi infection have shown a total infection rate of $45.2 \%(71 / 157)$ in domestic animals [3] and $18 \%(53 / 314)$ in native calves [21]. Other studies have reported infection rates of $16 \%(38 / 237)$ in pigs with diarrhea [22] and 14.9\% (80/538) in cattle [23], 1.9\% (4/210) in bat feces [30], 2.6\% (15/502) in wild boars [31], and 8.3\% (15/180) in milk specimens from cows [32]. As previously reported, the possibility of human infection is suggested by the continuous reports of Ent. bieneusi infections in domestic wildlife and livestock. Microsporidian spores remain viable in water after desiccation following incubation at various temperatures, suggesting that indirect zoonotic transmission of microsporidia between animals and humans could occur through exposure to contaminated water, food, or aerosols [6,40-42].

In this study, we detected Ent. bieneusi and Enc. intestinalis in domestic patients with diarrhea, providing the first evidence that Ent. bieneusi exists in humans in addition to animals in the ROK. Therefore, continuous monitoring for Enc. intestinalis and Ent. bieneusi is necessary for patients with acute diarrhea. In additon, epidemiologic analysis is needed to understand the infection pathways of Enc. intestinalis and Ent. bieneusi.

\section{Materials and Methods}

\subsection{Fecal Sample Collection and DNA Extraction}

A total of 1241 stool samples from patients with diarrhea were collected through the Enteric Pathogens Active Surveillance Network (Enter-Net) of the Korea Disease Control and Prevention Agency (KDCA) in 2020. The samples were examined for bacteria, viruses, and parasitic protozoa to determine the cause of diarrhea. 
Total DNA was extracted from $400 \mathrm{mg}$ stool samples using the Fast DNA SPIN kit for Soil (MP Biomedicals, Solon, OH, USA) according to the manufacturer's protocol. The extracted DNA was stored at $-20^{\circ} \mathrm{C}$ until PCR analysis.

\subsection{PCR Amplification}

Enc. intestinalis and Ent. bieneusi were detected using nested PCR, targeting the SSU rRNA [43]. The primers used for PCR amplification are listed in Table 1. The cycling conditions were as follows: the primary cycle consisted of $94{ }^{\circ} \mathrm{C}$ for $5 \mathrm{~min}$; 35 cycles of $94{ }^{\circ} \mathrm{C}$ for $30 \mathrm{~s}, 53{ }^{\circ} \mathrm{C}$ for $30 \mathrm{~s}$, and $72{ }^{\circ} \mathrm{C}$ for $90 \mathrm{~s}$; followed by $72{ }^{\circ} \mathrm{C}$ for $10 \mathrm{~min}$; and termination at $4{ }^{\circ} \mathrm{C}$. The second cycle consisted of $94{ }^{\circ} \mathrm{C}$ for $5 \mathrm{~min} ; 35$ cycles of $94{ }^{\circ} \mathrm{C}$ for $30 \mathrm{~s}, 55{ }^{\circ} \mathrm{C}$ for $30 \mathrm{~s}$, and $72{ }^{\circ} \mathrm{C}$ for $90 \mathrm{~s}$; followed by $72{ }^{\circ} \mathrm{C}$ for $10 \mathrm{~min}$; and termination at $4{ }^{\circ} \mathrm{C}$.

For genotyping Ent. bieneusi, a $390 \mathrm{bp}$ fragment of the ITS gene was amplified using nested PCR [44]. The primer sequences are listed in Table 1. The cycling conditions for Ent. bieneusi were as follows: the primary cycle consisted of $94{ }^{\circ} \mathrm{C}$ for $5 \mathrm{~min} ; 35$ cycles of $94{ }^{\circ} \mathrm{C}$ for $30 \mathrm{~s}, 57^{\circ} \mathrm{C}$ for $40 \mathrm{~s}$, and $72{ }^{\circ} \mathrm{C}$ for $40 \mathrm{~s}$; followed by $72{ }^{\circ} \mathrm{C}$ for $10 \mathrm{~min}$; and termination at $4{ }^{\circ} \mathrm{C}$. The second cycle consisted of $94^{\circ} \mathrm{C}$ for $5 \mathrm{~min}$; 35 cycles of $94^{\circ} \mathrm{C}$ for $30 \mathrm{~s}, 55{ }^{\circ} \mathrm{C}$ for $30 \mathrm{~s}$, and $72{ }^{\circ} \mathrm{C}$ for $40 \mathrm{~s}$; followed by $72{ }^{\circ} \mathrm{C}$ for $10 \mathrm{~min}$; and termination at $4{ }^{\circ} \mathrm{C}$.

\subsection{Nucleotide Sequencing and Phylogenetic Analysis}

The amplified Enc. intestinalis and Ent. bieneusi DNA fragments were sequenced using both forward and reverse primers (Table 2). The resulting nucleotide sequences were subjected to BLAST searches (https:/ /blast.ncbi.nlm.nih.gov/Blast.cgi accessed on 13 October 2021) using the data available on GenBank (http://www.ncbinlm.nih.gov/ genbank / accessed on 13 October 2021). Multiple alignments were conducted by ClustalW using BioEdit version 7.2.5 (Ibis Therapeutics Inc., Carlsbad, CA, USA). To determine the similarity and difference rates between the sequences, the MegaAlign program (DNASTAR, Madison, WI, USA) was employed. Finally, a phylogenetic analysis was performed with MEGA software (version 5.02) using the maximum parsimony algorithm with a Kimura two-parameter model assessed using bootstrap analysis with 1000 replications. Each sequence was identified by its accession number, host, origin, and genotype designation.

Table 2. List of PCR primers used in this study.

\begin{tabular}{|c|c|c|c|c|}
\hline Species & & & Sequence $\left(5^{\prime} \rightarrow 3^{\prime}\right)$ & Diagnostic Size \\
\hline \multirow{4}{*}{ Microsporidia spp. } & 1st & Mic A & GGAGCCTGAGAGATGGCT & \multirow{4}{*}{$\begin{array}{l}644 \mathrm{bp} \\
420 \mathrm{bp}\end{array}$} \\
\hline & & Mic E & AACGGCCATGCACCAC & \\
\hline & \multirow{2}{*}{ 2nd } & Mic C & GGTGCCAGCAGCCGCGG & \\
\hline & & Mic D & GCACAАТССАСТССТ & \\
\hline \multirow{4}{*}{ Ent. bieneusi } & \multirow{2}{*}{ 1st } & EBITS3 & GGTCATAGGGATGAAGAG & \multirow{2}{*}{$435 \mathrm{bp}$} \\
\hline & & EBITS4 & TTCGAGTTCTTTCGCGCTC & \\
\hline & 2nd & EBITS1 & GCTCTGAATATCTATGGCT & \multirow{2}{*}{$390 \mathrm{bp}$} \\
\hline & $2 \pi \mathrm{u}$ & EBITS2.4 & ATCGCCGACGGATCCAAGTG & \\
\hline
\end{tabular}

\subsection{Statistical Analysis}

Fisher's exact test was used to assess the association between Enc. intestinalis test positivity and factors such as sex and age group. Odds ratios and $95 \%$ confidence intervals were used to measure univariate associations. In this study, $p$-values $<0.05$ were considered statistically significant. All statistical analyses were performed using SPSS Statistics 23.0 (International Business Machines Corporation, New York, NY, USA). 
Author Contributions: Conceptualization, J.-W.J.; methodology, J.-Y.K. and J.-W.J.; investigation and data analysis, J.-Y.K. and J.-Y.S.; performing the experiments and resource collection, J.-Y.K. and J.-Y.S.; writing-original draft preparation, J.-Y.K.; writing-review and editing, J.-W.J., T.-Y.K. and H.-I.L.; supervision, J.-W.J. All authors have read and agreed to the published version of the manuscript.

Funding: This study was supported by funding from the Korea Disease Control and Prevention Agency (KDCA; 4837-311-210-13) of the Republic of Korea.

Institutional Review Board Statement: Ethical approval was not required because this study was conducted to evaluate public welfare through a fact-finding survey (Infectious Disease Control and Prevention Act).

Informed Consent Statement: Patient consent was suspended in this study because it was a retrospective analysis of specimens collected for legally stipulated research survey projects and no additional investigations were performed with the submitted specimens.

Data Availability Statement: The datasets generated during and/or analysed during the current study are available from the corresponding author on reasonable request.

Acknowledgments: We appreciate the 13 regional Institute of Health \& Environment members for collecting samples nationwide, including Gyeongsangnam-do, Gyeongsangbuk-do, Daegu, Daejeon, Busan, Seoul, Incheon, Jeollanam-do, Jeollabuk-do, Jeju, Chungcheong buk-do, Chungcheongnam-do and Gangwon-do Institute of Health \& Environment. This work was supported by a grant from the Korea Disease Control and Prevention Agency (KDCA; 4837-311-210-13). We also appreciate the assistance provided by Sean Sungsoo Choi (Korea Disease Control and Prevention Agency).

Conflicts of Interest: The authors declare no conflict of interest.

\section{References}

1. Ghoyounchi, R.; Ahmadpour, E.; Spotin, A.; Mahami-Oskouei, M.; Rezamand, A.; Aminisani, N.; Ghojazadeh, M.; Mikaeili-Galeh, T. Microsporidiosis in Iran: A systematic review and meta-analysis. Asian Pac. J. Trop. Med. 2017, 10, 341-350. [CrossRef]

2. Anane, S.; Attouchi, H. Microsporidiosis: Epidemiology, clinical data and therapy. Gastroenterol. Clin. Biol. 2010, $34,450-464$. [CrossRef]

3. Didier, E.S.; Weiss, L.M. Microsporidiosis: Current status. Curr. Opin. Infect. Dis. 2006, 19, 485-492. [CrossRef]

4. Goertz, D.; Solter, L.; Linde, A. Horizontal and vertical transmission of a Nosema sp. (Microsporidia) from Lymantria dispar (L.) (Lepidoptera: Lymantriidae). J. Invert. Path. 2007, 95, 9-16. [CrossRef]

5. Becnel, J.; Andreadis, T. Microsporidia in insects. In Microsporidia: Pathogens of Opportunity; Wiley-Blackwell: Hoboken, NJ, USA, 2014; pp. 521-570.

6. Didier, E.S.; Stovall, M.E.; Green, L.C.; Brindley, P.J.; Sestak, K.; Didier, P.J. Epidemiology of microsporidiosis: Sources and modes of transmission. Vet. Parasitol. 2004, 126, 145-166. [CrossRef] [PubMed]

7. Mclnnes, E.F.; Stewart, C.G. The pathology of subclinical infection of Encephalitozoon cuniculi in canine dams producing pups with overt encephalitozoonosis. J. S. Afr. Vet. Assoc. 1991, 62, 51-54. [CrossRef]

8. Han, B.; Takvorian, P.M.; Weiss, L.M. Invasion of host cells by microsporidia. Front. Microbiol. 2020, 11, 172-187. [CrossRef]

9. Coyle, C.M.; Wittner, M.; Kotler, D.P.; Noyer, C.; Orenstein, J.M.; Tanowitz, H.B.; Weiss, L.M. Prevalence of microsporidiosis due to Enterocytozoon bieneusi and Encephalitozoon (Septata) intestinalis among patients with AIDS-related diarrhea: Determination by polymerase chain reaction to the microsporidian small-subunit rRNA Gene. Clin. Infect. Dis. 1996, 23, 1002-1006. [CrossRef]

10. Deplazes, P.; Mathis, A.; Weber, R. Epidemiology and zoonotic aspects of microsporidia of mammals and birds. Contrib. Microbiol. 2000, 6, 236-260.

11. Cisse, O.A.; Ouattara, A.; Thellier, M.; Accoceberry, I.; Biligui, S.; Minta, D.; Doumbo, O.; Desportes-Livage, I.; Thera, M.A.; Danis, M.; et al. Evaluation of an immunofluorescent-antibody test using monoclonal antibodies directed against Enterocytozoon bieneusi and Encephalitozoon intestinalis for diagnosis of intestinal microsporidiosis in Bamako (Mali). J. Clin. Microbiol. 2002, 40, 1715-1718. [CrossRef] [PubMed]

12. Aseeja, P.; Shaikh, Y.; Bajpai, A.; Sirsikar, P.; Kalra, S.K. Advancement in our understanding of immune response against Encephalitozoon infection. Parasite Immunol. 2021, 43, e12828. [CrossRef] [PubMed]

13. Mathis, A.; Weber, R.; Deplazes, P. Zoonotic potential of the microsporidia. Clin. Microbiol. Rev. 2005, 18, 423-445. [CrossRef]

14. Enriquez, F.J.; Taren, D.; Cruz-López, A.; Muramoto, M.; Palting, J.D.; Cruz, P. Prevalence of intestinal encephalitozoonosis in Mexico. Clin. Infect. Dis. 1998, 25, 1227-1229. [CrossRef] [PubMed]

15. Qiu, L.; Xia, W.; Li, W.; Ping, J.; Ding, S.; Liu, H. The prevalence of microsporidia in China: A systematic review and meta-analysis. Sci. Rep. 2019, 9, 3174. [CrossRef] [PubMed]

16. Gool, T.V.; Vetter, J.C.; Weinmayr, B.; Dam, A.V.; Derouin, F.; Dankert, J. High seroprevalence of Encephalitozoon species in immunocompetent subjects. J. Infect. Dis. 1997, 175, 1020-1024. [CrossRef] [PubMed] 
17. Oyegue-Liabagui, S.L.; Ndjangangoye, N.K.; Kouna, L.C.; Lekolo, G.M.; Mounioko, F.; Kwedi Nolna, S.K.; Lekana-Douki, J.B. Molecular prevalence of intestinal parasites infections in children with diarrhea in Franceville, southeast of Gabon. BMC Infect. Dis. 2020, 20, 350. [CrossRef]

18. Halánová, M.; Valenčáková, A.; Jarčuška, P.; Halán, M.; Danišová, O.; Babinská, I.; Dedinská, K.; Čisláková, L. Screening of opportunistic Encephalitozoon intestinalis and Enterocytozoon bieneusi in immunocompromised patients in Slovakia. Cent. Eur. J. Public Health 2019, 27, 330-334. [CrossRef] [PubMed]

19. Kim, K.J.; Yoon, S.J.; Cheun, H.I.; Kim, J.H.; Sim, S.B.; Yu, J.R. Detection of Encephalitozoon spp. from human diarrheal stool and farm soil samples in Korea. J. Korean Med. Sci. 2015, 30, 227-232. [CrossRef] [PubMed]

20. Amer, S.; Kim, S.Y.; Han, J.I.; Na, K.J. Prevalence and genotypes of Enterocytozoon bieneusi in wildlife in Korea: A public health concern. Parasites Vectors 2019, 12, 160. [CrossRef]

21. Hwang, S.W.; Shin, S.U.; Kim, S.H.; Ryu, J.H.; Choi, K.S. Zoonotic potential of Enterocytozoon bieneusi in pre-weaned Korean native calves. Parasites Vectors 2020, 13, 300. [CrossRef] [PubMed]

22. Lee, J.H. Prevalence and molecular characteristics of Enterocytozoon bieneusi in cattle in Korea. Parasitol. Res. 2007, 101, 391-396. [CrossRef]

23. Jeong, D.K.; Won, G.Y.; Park, B.K.; Hur, J.; You, J.Y.; Kang, S.J.; Oh, I.G.; Lee, Y.S.; Stein, B.D.; Lee, J.H. Occurrence and genotypic characteristics of Enterocytozoon bieneusi in pigs with diarrhea. Parasitol. Res. 2007, 102, 123-128. [CrossRef]

24. Lobo, M.L.; Xiao, L.; Antunes, F.; Matos, O. Microsporidia as emerging pathogens and the implication for public health: A 10-year study on HIV-positive and -negative patients. Int. J. Parasitol. 2012, 42, 197-205. [CrossRef] [PubMed]

25. Kotler, D.P.; Orenstein, J.M. Clinical syndromes associated with microsporidiosis. Adv. Parasitol. 1998, 40, 321-349. [CrossRef]

26. Liu, H.; Jiang, Z.; Yuan, Z.; Yin, J.; Wang, Z.; Yu, B.; Zhou, D.; Shen, Y.; Cao, J. Infection by and genotype characteristics of Enterocytozoon bieneusi in HIV/AIDS patients from Guangxi Zhuang autonomous region, China. BMC Infect. Dis. 2017, 17, 684. [CrossRef] [PubMed]

27. Matos, O.; Lobo, M.L.; Xiao, L. Epidemiology of Enterocytozoon bieneusi infection in humans. J. Parasitol. Res. 2012, $2012,981424$. [CrossRef]

28. Henriques-Gil, N.; Haro, M.; Izquierdo, F.; Fenoy, S.; Águila, C. Phylogenetic approach to the variability of the Microsporidian Enterocytozoon bieneusi and its implications for inter- and intrahost transmission. Appl. Environ. Microbiol. 2010, 76, 3333-3342. [CrossRef]

29. Santín, M.; Fayer, R. Enterocytozoon bieneusi genotype nomenclature based on the internal transcribed spacer sequence: A consensus. J. Eukaryot. Microbiol. 2009, 56, 34-38. [CrossRef]

30. Lee, S.H.; Oem, J.K.; Lee, S.M.; Son, K.D.; Jo, S.D.; Kwak, D.M. Molecular detection of Enterocytozoon bieneusi from bats in South Korea. Med. Mycol. 2018, 56, 1033-1037. [CrossRef]

31. Lee, H.S.; Seo, M.G.; Lee, S.H.; Oem, J.K.; Kim, S.H.; Jeong, H.S.; Kim, Y.K.; Jheong, W.H.; Kwon, O.D.; Kwak, D.M. Distribution and genotypic analysis of Enterocytozoon bieneusi from wild boars in Korea. Med. Mycol. 2021, 59, 934-938. [CrossRef] [PubMed]

32. Lee, J.H. Molecular detection of Enterocytozoon bieneusi and identification of a potentially human-pathogenic genotype in milk. Appl. Environ. Microbiol. 2008, 74, 1664-1666. [CrossRef]

33. Shen, Y.; Gong, B.; Liu, X.; Wu, Y.; Yang, F.; Xu, J.; Zhang, X.; Cao, J.; Liu, A. First identification and genotyping of Enterocytozoon bieneusi in humans in Myanmar. BMC Microbiol. 2020, 20, 10. [CrossRef]

34. Zhao, W.; Zhang, W.; Yang, F.; Zhang, L.; Wang, R.; Cao, J.; Shen, Y.; Liu, A. Enterocytozoon bieneusi in dairy cattle in the northeast of China: Genetic diversity of ITS gene and evaluation of zoonotic transmission potential. J. Eukaryot. Microbiol. 2015, 62, 553-560. [CrossRef] [PubMed]

35. Sulaiman, I.M.; Fayer, R.; Lal, A.A.; Trout, J.M.; Schaefer, F.W.; Xiao, L. Molecular characterization of microsporidia indicates that wild mammals harbor host-adapted Enterocytozoon spp. as well as human-pathogenic Enterocytozoon bieneusi. Appl. Environ. Microbiol. 2003, 69, 4495-4501. [CrossRef]

36. Jacques, B.; Emmanuelle, B.D.; Sylvestre, B.; Alessandra, C.; Xavier, S.; Madeleine, O.N.; Chantal, N.; Maryvonne, K.; Isabelle, A.; Marc, T. New highly divergent rRNA sequence among biodiverse genotypes of Enterocytozoon bieneusi strains isolated from humans in Gabon and Cameroon. J. Clin. Microbiol. 2007, 45, 2580-2589.

37. Li, N.; Xiao, L.; Wang, L.; Zhao, S.; Zhao, X.; Duan, L.; Guo, M.; Liu, L.; Feng, Y. Molecular Surveillance of Cryptosporidium spp., Giardia duodenalis, and Enterocytozoon bieneusi by Genotyping and Subtyping Parasites in Wastewater. PLoS Negl. Trop. Dis. 2012, 6, e1809. [CrossRef] [PubMed]

38. Thellier, M.; Breton, J. Enterocytozoon bieneusi in human and animals, focus on laboratory identification and molecular epidemiology. Parasite 2008, 15, 349-358. [CrossRef] [PubMed]

39. Karim, M.R.; Dong, H.; Li, T.; Yu, F.; Li, D.; Zhang, L.; Li, J.; Wang, R.; Li, S.; Li, X.; et al. Predomination and new genotypes of Enterocytozoon bieneusi in captive nonhuman primates in zoos in China: High genetic diversity and zoonotic significance. PLoS ONE 2015, 10, e0117991. [CrossRef]

40. Zhang, Y.; Koehler, A.V.; Wang, T.; Gasser, R.B. Enterocytozoon bieneusi of animals—With an 'Australian twist'. Adv. Parasitol. 2021, 111, 1-73. [PubMed]

41. Lesnianska, K.; Perec-Matysiak, A. Wildlife as an environmental reservoir of Enterocytozoon bieneusi (Microsporidia) analyses of data based on molecular methods. Ann. Parasitol. 2017, 63, 265-281.

42. Pepper, I.L.; Gerba, C.P.; Gentry, T.J. Environmental Microbiology, 3rd ed.; Elsevier: Amsterdam, The Netherlands, 2015; pp. 509-550. 
43. Lee, S.H.; Joung, M.G.; Yoon, S.J.; Choi, K.J.; Park, W.Y.; Yu, J.R. Multiplex PCR detection of waterborne intestinal Protozoa: Microsporidia, Cyclospora, and Cryptosporidium. Korean J. Parasitol. 2010, 48, 297-301. [CrossRef] [PubMed]

44. Zang, M.; Li, J.; Tang, C.; Ding, S.; Huang, W.; Qin, Q.; Liu, H. Prevalence and phylogenetic analysis of Microsporidium Enterocytozoon bieneusi in diarrheal patients. Pathogens 2021, 10, 128. [CrossRef] [PubMed] 